\title{
Stress, Religious Coping and Wellbeing in Acculturating Muslims
}

\section{Zeenah Adam \\ Colleen Ward}

Victoria University of Wellington

Correspondence regarding this paper should be addressed to Zeenah Adam. E-mail: zeenahadam@gmail.com

\begin{abstract}
Situated within an international context of Islamophobia, this study examined acculturative stress, religious coping, and their interaction as predictors of subjective wellbeing in 167 New Zealand Muslims. A Muslim Religious Coping (MRC) scale was adapted for the purposes of this study, measuring religious coping across three domains of Cognitive, Behavioral, and Social MRC. Consistent with hypotheses: 1) acculturative stress predicted a lower level of Life Satisfaction and more psychological symptoms, and 2) Behavioral, Cognitive and Social MRC predicted greater Life Satisfaction. In addition, an interaction effect between Acculturative Stress and Behavioral MRC was found indicating that engaging in religious practices buffered the detrimental effects of acculturative stress on life satisfaction. Contrary to the hypotheses, however, MRC did not demonstrate a main or interaction effect on psychological symptoms. The implications of these findings are discussed in relation to positive and negative indicators of wellbeing, the importance of religious maintenance as a resource for acculturating Muslims living in a Western country, and the implications for counselors working with Muslim clients.
\end{abstract}

Keywords: acculturation, stress, coping, wellbeing, Muslim Stress, Religious Coping and Wellbeing in Acculturating Muslims

While coping with intercultural contact can be a stressful experience for minority ethnic, cultural, and religious groups in culturally plural societies, it presents particular challenges for Muslims living in Western countries in a post-9/11 
world (Ward, Bochner, \& Furnham, 2001; Jasperse, Ward, \& Jose, 2012). Despite evidence that religiosity and spirituality are associated with positive outcomes for health and quality of life (Hackney \& Sanders, 2003; Sawatzky, Ratner, \& Chiu, 2005), widespread and increasing Islamophobia (Sheridan, 2006) may diminish the positive contribution that religion can make to coping with acculturative stress and enhancing wellbeing for Muslims. This research combines theory and research on acculturation (Berry, 1997; Berry, \& Sam, 2016) and religion (Pargament, 1997, 2011) to explore the role of religious coping in buffering stress and enhancing subjective wellbeing in New Zealand Muslims.

\section{Acculturation and Adaptation}

Acculturation theory posits that crossing cultures, whether in reference to international migration or sustained intercultural interactions within national borders, is typically stressful (Berry, 2006; Ward, 2011). Intercultural contact evokes appraisal to determine the level of perceived stress and to assess coping resources, which are subsequently activated to master, tolerate, reduce, or control stress. A wide range of coping techniques are available, including problemand emotion-focused coping, positive reframing and acceptance, and seeking social support (Aroian et al., 2009; Crockett et al., 2007; Jibeen \& Khalid, 2010; Kloek, Peters, \& Sijtsma, 2013). When these coping strategies are effective and successful, acculturation leads to adaptation, that is, psychological and emotional wellbeing.

Although the framework for the study of acculturative stress arises from Lazarus and Folkman's (1984) generic Transactional Model of Stress, in this case there are important conceptual and measurement issues that merit special consideration. First and foremost is the definition and assessment of acculturative stress, defined by Berry (2006, p. 294) as "a stress reaction in response to life events that are rooted in the experience of acculturation." Clearly, stresses associated with aspects of cross-cultural transition (e.g., communication difficulties) and discrimination (e.g., exclusion on the basis of ethnic or religious background) are forms of acculturative stress (Joiner \& Walker, 2002; Stuart, 2012); however, it has also been argued that more general life stresses, such as financial strain or conflict with family members, should be included among acculturative stresses when these occur in acculturating minority and immigrant groups (e.g., Ritsner, Modai, \& Ponizovsky, 2000).

Not only are the domains of acculturative stress debated, but also the method in which they are assessed. It is not sufficient to quantify the number of stressors encountered as there are large individual differences in stress appraisal. Rather, it is important to include both the occurrence and evaluation of stressful life events in the assessment of acculturative stress (see Jose, Ward, 
\& Liu, 2007; Szabo, Ward, \& Jose, 2016). Finally, it is necessary to distinguish acculturative stress from stress outcomes (Rudmin, 2009). Far too often acculturative stress has been confounded with psychological symptoms or decrements in wellbeing. Berry's $(1997,2006)$ framework for the study of acculturative stress clearly delineates the major components of the stress and coping process, including the appraisal of intercultural contact, the experience of acculturative stress, the implementation of coping resources and the resultant adaptive outcomes.

Although psychological adaptation is a broad and multi-faceted construct, in acculturation theory and research on stress and coping it is often discussed in terms of subjective wellbeing (Diener, 1994). According to Diener (2006, p. 399) subjective wellbeing refers to "the various types of evaluations, both positive and negative, that people make of their lives." Life satisfaction is a key indicator of subjective wellbeing, although Diener $(1994,2006)$ argues that both positive and negative indicators of subjective wellbeing present a more comprehensive and informative picture of processes and outcomes. Along these lines, it is common for acculturation researchers to use both positive (e.g., life satisfaction) and negative (e.g., psychological and behavioral symptoms) indicators of subjective wellbeing in their research (e.g., Berry, Phinney, Sam, \& Vedder, 2006; Jasperse et al., 2012; Stuart, Ward, \& Robinson, 2016).

\section{The Role of Religion in Coping with Stress}

Religious coping refers to the use of cognitive-behavioral techniques to manage stressful situations in light of one's spirituality or religious beliefs (Pargament, 1997). Epidemiological studies indicate people frequently rely on religion to cope with life stresses, with meta-analyses demonstrating positive impacts of religious coping on wellbeing (Ano \& Vasconcelles, 2005; Harrison, Koenig, Hays, Eme-Akwari, \& Pargament, 2001). Additionally, a smaller number of studies has found religious coping to moderate the relationship between stress and wellbeing, providing support for the buffering hypothesis (Aydin, Fischer, \& Frey, 2010; Carpenter, Laney, \& Mezulis, 2012; Fernandez \& Loukas, 2014; Tix \& Frazier, 1998). These findings elucidate the two mechanisms by which coping can affect adaptation outcomes (Ensel \& Lin, 1991). The first positions coping resources as independently affecting adaptation (main effect hypothesis). The second situates coping resources as intervening variables, functioning to diminish the negative effects of stress on wellbeing (buffering hypothesis).

Research has identified a variety of ways that people use religion to cope, including engaging in religious practices, seeking social support through religious leaders and congregations, and reframing stressful events in reference to their relationship with God (Boudreaux, Catz, Ryan, Amaral-Melendez, 
\& Brantley, 1995; Krägeloh, Chai, Shepherd, \& Billington, 2012; Pargament, Smith, Koenig, \& Perez, 1998). While some researchers have focused more exclusively on the cognitive aspects of religious coping (Pargament et al., 1998), others have explored the importance of outward religious practices and social support accessed via religious networks (Boudreaux et al., 1995) with results suggesting that different facets of religious coping may differentially impact wellbeing outcomes. These findings highlight the potential independence of cognitive, behavioral, and social dimensions of religious coping.

The vast majority of studies examining religious coping has focused on Christian populations living as a Western majority. More recently, however, ethnic minorities living as long-term residents in Western countries have begun to receive attention. This line of research indicates that disempowered and deprived groups, including women and ethnic minorities, not only tend to use religious coping more often, but also derive a greater sense of efficacy from it (Harrison et al., 2001). In addition, religious coping has been shown to be utilized more heavily at times when situations are appraised as uncontrollable or perceived as greatly exceeding one's resources (Pargament, 1997; Tix \& Frazier, 1998), thus providing an outlet for those at a social disadvantage and with limited access to external resources.

Religious coping among Muslims. Because the religious coping literature has focused predominantly on the Judeo-Christian population, relatively less is known about the efficacy of religious coping among Muslims (Abu Raiya, Pargament, Mahoney, \& Stein, 2008). For many Muslims, Islam is considered a comprehensive way of life that permeates cognitive, affective, behavioral, and spiritual components of the self (Abu Raiya \& Pargament, 2011). It is likely, then, that when confronted with a stressor, Muslims will consider religion a resource in managing their distress. Indeed, research indicates that Muslims engage religion as a coping mechanism in response to stress at high rates relative to other religious groups (Bhui, King, Dein, \& O'Connor, 2008; Cinnirella \& Loewenthal, 1999). Additionally, the multi-faceted nature of Muslim religious coping has been highlighted with specific emphasis on both its inner (i.e., one's personal relationship with God) and outer (one's religious rituals and interactions with others) aspects as crucial components of the faith (Abu Raiya et al., 2008; Khan \& Watson, 2006).

Research focusing exclusively on Muslim populations has found mixed results for the efficacy of religious coping (Aflakseir \& Coleman, 2009; Aflakseir \& Coleman, 2011; Gardner, Krägeloh, \& Henning, 2014; Hassouneh-Phillips, 2003; Khan \& Watson, 2006). Hassouneh-Phillips' (2003) investigation of the use of religious coping among Muslim women survivors of domestic violence provided evidence for religion as a source of both strength and vulnerability in this population. As a source of strength, religious practices such as prayer and Quranic recitation provided an important means for coping; as a vulnerability, religious and cultural beliefs prevented some women from seeking help by promoting an 
attitude of acceptance and patience with their predicament. In contrast, Aflakseir and Coleman $(2009,2011)$ examined religious coping among Muslim students and war veterans in Iran. They found that religious coping predicted enhanced psychological adjustment in the student sample and reduced levels of PTSD and psychosomatic symptoms among disabled war veterans.

Religious coping and acculturative stress among Muslims in the West. While Muslims residing in the West represent an extremely diverse range of people, there are some common threads running through their experiences. Muslims in the West have been described as living on the 'crossroads of global conflict' (Sirin \& Fine, 2007). In addition to the common difficulties associated with cultural transition, such as language barriers, financial struggles and social isolation, two particularly salient acculturative challenges currently facing Muslims include religious discrimination and barriers to practicing their religion as a consequence of Islamophobia (Sheridan, 2006).

A growing body of research has documented the increase in Islamophobic attitudes in many Western countries along with their negative consequences for Muslim immigrants and their descendants (Abu-Raiya, Pargament, \& Mahoney, 2011; Pedersen, Dunn, Forrest, \& McGarty, 2012; Sheridan, 2006). These include difficulties in obtaining employment, social exclusion, harassment and suspicion. Several studies have pointed towards the role of religion in coping with these acculturative challenges (Abu Raiya et al., 2011; Ahmed, Kia-Keating, \& Tsai, 2011; Aydin et al., 2010; Gardner et al., 2014). Aydin et al.s (2010) study of Turkish-German Christians and Muslims facing racial discrimination and segregation found religious coping to significantly buffer the effects of acculturative stress on wellbeing. A study of the experiences of American Muslims dealing with stressful events post-9/11 found that the use of religious coping was related to increased post-traumatic growth (Abu Raiya et al., 2011). Ahmed and colleagues (2011) surveyed the influence of cultural resources (ethno-cultural identity and religious coping) on acculturative stress among Arab-American Christians and Muslims. While acculturative stress predicted poor mental health outcomes, greater use of religious coping predicted less depression and anxiety. Taken together, emerging evidence points towards religion as a protective factor among Muslims experiencing acculturative stress, with religious coping independently enhancing wellbeing and moderating the negative effects of acculturative stress on adaptation.

\section{The Present Study}

The present study investigates acculturative stress and religious coping as predictors of wellbeing in Muslim immigrants and their descendants in New Zealand. The study advances our understanding of the everyday experiences and subjective wellbeing of Muslims in Western countries by synthesizing theory 
and research from acculturation psychology and the psychology of religion. To achieve these ends, the research employs a sophisticated measurement of acculturative stress and a culturally appropriate assessment of religious coping. Before we outline our hypotheses, however, we provide a brief description of the research setting as many readers may be unfamiliar with the New Zealand context.

The New Zealand context. New Zealand is traditionally a bicultural nation with the Treaty of Waitangi, an agreement between British colonizers and indigenous Maori, regarded as the foundation of contemporary New Zealand sovereignty (Liu, Wilson, McClure, \& Higgins, 1999). However, changes in immigration policy in the late 1980s and early 1990s resulted in a dramatic increase in ethnic, cultural and religious diversity and New Zealand's evolution into a multicultural nation (Ward \& Liu, 2012). Recent census data indicate that the population of Muslims in New Zealand is now 46,149, just over $1 \%$ of the country's 4.5 million population (Statistics New Zealand, 2013).

While New Zealanders generally tend to endorse a multicultural ideology (Ward \& Masgoret, 2008), they perceive immigrants originating from preodminantly Muslim countries less favorably than those from other nations, indicating that this remote country is not immune to Islamophobic attitudes (Stuart, Ward, \& Adam, 2010). However, in spite of this, preliminary findings within the New Zealand Muslim community consistently point to a population that is adapting remarkably well (Jasperse et al., 2012; Stuart, 2012; Stuart et al., 2010; Stuart \& Ward, 2011). The current study aims to contribute to this growing area of research.

Research aims and hypotheses. In summary, this study explores acculturative stress, religious coping and their interaction as predictors of subjective wellbeing among Muslims in New Zealand. In light of the research reviewed in the previous sections, the hypotheses are:

1. Acculturative stress will negatively predict subjective wellbeing, and Muslim religious coping will positively predict subjective wellbeing (i.e., greater life satisfaction and fewer psychological symptoms).

2. Muslim religious coping will buffer the negative impact of stress on subjective wellbeing.

\section{Method}

Participants and Procedure

One hundred and sixty-seven Muslims living in New Zealand participated in this study. The participants had a mean age of $31.5(S D=9.92)$, and $64.7 \%$ were 
female. A diverse range of ethnicities were represented in the sample, including Indian/South Asian (32.9\%), East Asian (17.4\%), Middle Eastern (16.8\%), European (16.2\%), African (9.0\%), and Maori/Pacific Islander (4.8\%). The participants identified as highly religious $(M=4.88, S D=0.45)$ as assessed by responses to the question "How Important is Islam to you?" on a 5-point scale $(1=$ Not at all, $5=$ Very $)$.

The majority of participants were New Zealand citizens (69.5\%), and 29.9\% were New Zealand-born. The mean length of time spent in New Zealand for foreign-born participants was 15.81 years $(S D=11.55)$, and the level of selfreported English language proficiency was high; $M=4.58(S D=0.68)$ on a 5-point (very poor/very good) scale.

Participants were recruited through social media groups and community e-mail networks to complete an anonymous survey. The survey was available on-line via Qualtrics software and was administered in English.

\section{Measures}

The survey included background information of age, gender, citizenship, education level, ethnicity, generation status, English proficiency and religiosity along with measures of acculturative stress, coping, and subjective wellbeing (life satisfaction and psychological symptoms).

Acculturative Stress. The 26-item measurement of stressful life events was based on a compilation of instruments by Jose et al. (2007) and Stuart (2012), previously used to assess the acculturative stress experienced by short and long term immigrants in New Zealand, including New Zealand Muslims. The measurement by Jose and colleagues (2007) was designed to capture general stressors (e.g., relationship difficulties, financial strain) encountered by acculturating international students. The instrument's construct validity was supported by established group differences with Asian international students, characterized by a high level of cultural distance, reporting more stress than either local or Western international students. Moreover, stress predicted negative adjustment over time. Jose et al. (2007) reported that the instrument possessed good internal reliability (alpha $=.87)$. The measure by Stuart $(2012)$ assessed cultural transition stress (e.g., communication difficulties, social isolation) and ethnic/religious discrimination stress (e.g., harassment, exclusion on the basis of ethnic or religious background) in Muslim youth in New Zealand. These measures demonstrated good internal consistency (alphas $=.87-.90)$, were strongly inter-related $(r=.52)$ and inversely correlated with English language proficiency (Stuart, 2012). The general, transition and discrimination stress measures from Jose and colleagues (2007) and from Stuart (2012) were subjected to confirmatory factor analysis as reported in Adam (2015) and demonstrated a good fit to a single factor model, i.e., a latent variable labelled Acculturative Stress. 
For each of the 26 items on the Acculturative Stress measure participants first indicated if a specified event (e.g., disrespectful treatment) had happened to them in the previous three months, and if so, rated how much distress the event had caused them on a 5-point scale (endpoints: not at all/very distressed), so that higher scores indicate greater acculturative stress. The Acculturative Stress score was computed as a sum of the perceived distress associated with each individual's unique combination of stressors. This resulted in large variation between individual scores, which ranged from a possible minimum of 0 and maximum of 130.

Muslim Religious Coping. The 24-item measure of Muslim Religious Coping (MRC) was based on scales by Aflakseir and Coleman (2011) and Boudreaux and colleagues (1995). Details about the construction and validation of the three-factor (cognitive, behavioral, social) religious coping measure designed for use with a heterogeneous minority Muslim population is reported in Adam (2015). ${ }^{1}$ Cognitive items examined the way participants interpreted God's role in their stressful circumstances (e.g., seeing my situation as Allah's will); behavioral items explored the use of religious rituals as a means of coping with stress (e.g., reading the Quran); and social items examined the ways participants sought help, advice and solace from the Muslim community (e.g., looking for love and concern from members of the mosque). A prompt advised participants to rate their use of each coping method according to the way they had responded to the stressors identified previously. For each item, participants rated the extent to which they had engaged in a given coping strategy on a 5-point scale (endpoints: not at all/a lot) with a higher score indicating a more frequent use of the coping strategy.

Psychological wellbeing. Positive and negative measures of subjective wellbeing were examined via two scales that have demonstrated good validity and reliability with immigrant populations across a variety of cultural contexts, including New Zealand (Berry et al., 2006; Jasperse et al., 2012; Kuppens, Realo, \& Diener, 2008).

Life satisfaction was measured using Diener, Emmons, Larsen and Griffin's (1985) 5-item Satisfaction with Life scale (SWLS). Participants responded on a 5-point agree/disagree scale indicating the extent to which they agreed with statements such as "The conditions of my life are excellent." A higher score indicates a greater sense of satisfaction with one's life. Diener et al. (1985) reported high internal consistency (alpha $=.87$ ) and temporal stability (test-retest coef-

1. After conducting the PCA, the original 28 items were reduced to 24 items. Convergent validity was established relating the MRC subscales to subscales of Carver, Scheier and Weintraub's (1989) COPE. As specified, Cognitive MRC was related to Acceptance $(r=.33, p<0.01)$ and Positive Reframing and Growth $(r=.48, p<0.01)$; Behavioral MRC was related to Active Coping $(r=.27, p<0.001)$ and Planning $(r=.28, p<0.001)$; Social MRC was related to Emotional $(r=.23, p<0.01)$ and Instrumental $(r=.28, p<0.01)$ Social Support. Further information is available from the first author. 
ficient $=.82)$ at the time of the scale construction. The initial construct validation was based on known group differences, i.e., low scores found in groups such as psychiatric patients, prisoners, and abused women. In their early review of the SWLS, Pavot and Diener (1993) provided additional evidence for convergent validity with alternative assessments of life satisfaction and subjective wellbeing. More recently, the SWLS has been used in International Comparative Study for Ethno-cultural Youth, a 13-nation cross-cultural study, which confirmed its unifactorial structural equivalence (Berry et al., 2006) and in studies of New Zealand Muslims, which demonstrated the measure's internal consistency with alphas > .80 (Jasperse et al., 2012; Stuart et al., 2016).

Psychological symptoms were measured using a 15-item scale initially developed for the International Comparative Study for Ethno-cultural Youth (Berry et al., 2006). Participants rated on a 5-point scale (endpoints: never/very often) how often they had experienced a range of symptoms (depression, anxiety and somatic symptomatology) in the previous month. A higher score indicated higher levels of psychological symptoms (i.e., poorer psychological wellbeing). The initial psychometric analyses of the instrument confirmed its single factor structure and strong internal consistency across 13 countries (Berry et al., 2006). The measure has been subsequently used Jasperse et al.s (2012) study of New Zealand Muslims and proved psychometrically robust $($ alpha $=.94)$.

\section{Results}

\section{Preliminary Analyses}

The factor structure of Muslim Religious Coping (MRC). Due to the exploratory nature of the newly developed measure of Muslim Religious Coping, a principle components analysis of MRC items was computed via direct oblimin rotation $($ delta $=0)$, resulting in a three- factor solution (Table 1) and explaining $65.8 \%$ of the variance. A 0.91 Kaiser-Meyer-Olkin value exceeded the recommended requirement of 0.60 , and Bartlett's Test of Sphericity was significant $\left(X^{2}(190)=\right.$ $2310.10, p<.001)$. As predicted, the three factors loaded according to the hypothesized dimensions of Cognitive Religious Coping, Behavioral Religious Coping and Social Religious Coping. Factor loadings above 0.5 for the item's converging factor and below 0.3 on divergent factors were taken as minimum criteria.

The three subscales of Muslim Religious Coping (MRC) were significantly positively correlated (Table 2), suggesting that they represent an underlying construct of religious coping. Social MRC was moderately correlated with the other two subscales (Cognitive $r(165)=.34$, Behavioral $r(165)=-.37$ ), whereas Cognitive and Behavioral MRC factors were strongly inter-correlated $(r(165)$ $=0.73, p<.01)$. 
Table 1. The Factor Structure of Muslim Religious Coping

\begin{tabular}{llll}
\hline & 1 & 2 & 3 \\
\hline Cognitive Religious Coping & & & \\
Seeing my situation as Allah's will & .90 & .17 & .04 \\
Seeking patience because Allah is with those who are patient &. $\mathbf{8 3}$ & .08 & .12 \\
Telling myself that suffering may bring me closer to Allah & .77 & .08 & .02 \\
Looking for a lesson from Allah in the situation & .76 & .04 & .02 \\
Seeing my suffering as purification of my sins & .74 & .00 & .18 \\
Viewing my situation as a trial from Allah & .71 & .05 & .10 \\
Trying to make up for my mistakes & .71 & .01 & .04 \\
Trying to remember my blessings and thank Allah & .61 & .17 & .16 \\
Asking for Allah's forgiveness & .59 & .23 & .08 \\
& & & \\
Behavioral Religious Coping & & & \\
Reading certain dua & .12 & .91 & .01 \\
Seeking guidance by reading Qur'an & .02 &. $\mathbf{8 4}$ & .07 \\
Seeking help with prayer & .06 & .79 & .01 \\
Reading the Qur'an & .00 & .77 & .08 \\
Increasing prayers to Allah & .09 & .75 & .08 \\
Praying for Allah's love and mercy & .17 & .73 & .08 \\
Seeking tranquillity through remembrance of Allah & .21 & .64 & .05 \\
Social Religious Coping & & & \\
Attending events at the mosque & & & \\
Attending religious classes & .02 & .05 & $\mathbf{. 8 8}$ \\
Volunteering for a religious cause & .09 & .01 & $\mathbf{. 8 5}$ \\
Looking for love and concern from members of the mosque & .05 & .07 & .04 \\
\hline
\end{tabular}

Table 2. Psychometric Properties of the Scales and Bivariate Correlations

\begin{tabular}{lrrrrccccc}
\hline & Items & M & SD & alpha & 2 & 3 & 4 & 5 & 6 \\
\hline 1. Cognitive MRC & 9 & 3.88 & 0.94 & .92 & $.73^{\star \star}$ & $.34^{\star \star}$ & .08 & $.16^{\star}$ & $.24^{\star \star}$ \\
2. Behavioral MRC & 7 & 3.60 & 1.08 & .92 & - & $.37^{\star \star}$ & .03 & $.20^{\star}$ & .13 \\
3. Social MRC & 4 & 2.35 & 1.16 & .85 & & - & -.03 & $.22^{\star \star}$ & .13 \\
4. Psychological Symptoms & 15 & 2.66 & 0.85 & .93 & & & - & $-.38^{\star \star}$ & $.38^{\star \star}$ \\
5. Life Satisfaction & 5 & 3.52 & 0.86 & .84 & & & & - & $-.17^{\star}$ \\
6. Acculturative Stress & 26 & 33.43 & 21.27 & .94 & & - & & & - \\
\hline
\end{tabular}

${ }^{\star} p<.05 .{ }^{* \star} p<.01$.

\section{Psychometric analyses, descriptive statistics and inter-correlations.}

Cronbach alphas, means, standard deviations and inter-correlations are reported in Table 2. Psychometric analyses indicated that all Cronbach alphas exceeded .80, demonstrating an acceptable level of internal consistency for all measures. Correlational analyses revealed that acculturative stress was negatively correlated with life satisfaction $(r(165)=-.17, p=.03)$ and positively related to psychological symptoms $(r(165)=.38, p<.01)$. Behavioral, cognitive and social dimensions of Muslim religious coping were positively and signifi- 
Table 3. The Prediction of Life Satisfaction: Beta Weights

\begin{tabular}{|c|c|c|c|c|c|c|c|c|}
\hline & B & $\begin{array}{l}\text { Cognitive } \\
\text { MRC }\end{array}$ & $\begin{array}{c}\text { Behavioral } \\
\text { MRC }\end{array}$ & $\begin{array}{l}\text { Social } \\
\text { MRC }\end{array}$ & & & & \\
\hline Regression Step & 1 & 2 & 3 & 4 & 3 & 4 & 3 & 4 \\
\hline \multicolumn{9}{|l|}{ 1. Demographics } \\
\hline Age & .14 & .16 & .16 & .16 & .14 & .12 & $.17^{\star}$ & $.18^{\star}$ \\
\hline Generation Status & -.03 & -.09 & -.04 & -.04 & -.04 & -.04 & -.08 & -.08 \\
\hline Education Level & .07 & .03 & .03 & .03 & .05 & .03 & -.02 & -.03 \\
\hline English Proficiency & .07 & .04 & .08 & .08 & .08 & .08 & .12 & .13 \\
\hline \multicolumn{9}{|l|}{ 2. Stress } \\
\hline Acculturative Stress & & $-.22^{\star \star}$ & $-.26^{\star \star}$ & -.51 & $-.23^{\star \star}$ & $-.89^{\star \star}$ & $-.25^{\star \star}$ & $-.53^{\star *}$ \\
\hline \multicolumn{9}{|l|}{ 3. MRC } \\
\hline Cognitive MRC & & & $.20^{\star}$ & .13 & & & & \\
\hline Behavioral MRC & & & & & $.19^{\star}$ & -.10 & & \\
\hline Social MRC & & & & & & & $.30^{\star \star}$ & .09 \\
\hline \multicolumn{9}{|l|}{ 4. Interaction } \\
\hline Stress $\times$ Cognitive MRC & & & & .28 & & & & \\
\hline Stress $\times$ Behavioral MRC & & & & & & $.79^{\star}$ & & \\
\hline Stress x Social MRC & & & & & & & & 0.39 \\
\hline $\mathrm{R}^{2}$ & .035 & $.078^{\star}$ & $.11^{*}$ & .11 & $.11^{\star}$ & $.14^{*}$ & $.16^{\star \star}$ & .18 \\
\hline $\mathrm{R}^{2}$ change & .035 & $.042^{\star}$ & $.034^{\star}$ & .003 & $.031^{\star}$ & $.033^{\star}$ & $.078^{\star \star}$ & .019 \\
\hline
\end{tabular}

${ }^{*} p<0.05 ;{ }^{* *} p<0.01$

The table reports the results of three separate regression equations for the prediction of life satisfaction by cognitive, behavioral or social Muslim religious coping. Steps 1 (control variables) and 2 (acculturative stress) are common to all equations and are presented in the far left column. The third and fourth steps are reported separately for each religious coping domain. For the first analysis, Cognitive MRC is entered as a main effect at Step 3, and interaction effect at Step 4 (results presented in the second column). Behavioural MRC is similarly presented in the third column, and Social MRC is presented in the final column.

cantly associated with life satisfaction ( $r$ s ranged from .16 to .22), but unrelated to psychological symptoms.

\section{Predicting Subjective Wellbeing}

Hierarchical regression analyses were conducted with acculturative stress and Muslim religious coping as predictors of subjective wellbeing outcomes (life satisfaction and psychological symptoms), after controlling for demographic variables. To avoid problems of multicollinearity between MRC subscales, which were strongly inter-related, separate regression analyses were performed for each individual dimension of Muslim religious coping.

Acculturative stress and Muslim religious coping as predictors of life satisfaction. Table 3 reports the results of three separate hierarchical regression equations for the prediction of life satisfaction. In each regression, control 
variables are entered at Step 1, acculturative Stress is entered at Step 2, and religious coping (cognitive, behavioral or social) is entered in the third step. In the final step, the interaction between acculturative stress and religious coping (cognitive, behavioral or social) is added to the equation.

At Step 1, the control variables of age, education, English proficiency and generational status were entered into the hierarchical regression analyses, as these variables have been previously identified in the literature as significant contributors to adaptation outcomes (e.g. Torres \& Rollock, 2004). None of these variables were significant at Step 1. At Step 2, acculturative stress was entered into the analysis, emerging as a significant predictor $(\beta=-0.22, t=-2.54$, $p=.01)$, and explaining a total of $7.8 \%$ of the variance $\left(\Delta R^{2}=0.042, F(1,141)=\right.$ $6.46, p=.04)$ in life satisfaction. Increased acculturative stress predicted lower life satisfaction.

MRC subscales were entered at Step 3 into three separate regression equations. All three MRC subscales independently predicted enhanced life satisfaction (Cognitive $\beta=0.20, t=2.30, p=.02$; Behavioral $\beta=0.19, t=2.19, p=.03$; Social $\beta=0.30, t=3.60, p<.001$ ), supporting our main effects hypothesis that both acculturative stress and Muslim religious coping would independently predict life satisfaction.

At Step 4, interaction variables of acculturative stress and MRC subscales were entered into the three regression analyses. As Cognitive MRC and Social MRC failed to moderate the relationship between acculturative stress and life satisfaction (Cognitive MRC $\mathrm{x}$ acculturative stress $\Delta R^{2}=0.003, F(1,139)=$ $0.39, p=.53$; Social MRC $\mathrm{x}$ acculturative stress $\Delta R^{2}=0.019, F(1,139)=3.21, p$ $=.08$ ), the final results of these equations were interpreted from Step 3. For Behavioral MRC, the significant main effect was qualified by an interaction with acculturative stress $(\beta=0.79, t=2.30, p=.02)$, explaining a total of $14.1 \%$ of the variance in life satisfaction $\left(\Delta R^{2}=0.033, F(1,139)=5.30, p=.02\right)$.

This significant interaction was plotted in Figure 1 using Modgraph (Jose, 2013). The interaction plot revealed that acculturative stress was unrelated to life satisfaction under conditions of high Behavioral MRC (High slope = $-0.003, t(144)=-0.84, p=.40)$; however, acculturative stress was associated with diminished life satisfaction for participants who engaged in medium or low levels of Behavioral MRC (Medium slope $=-0.01, t(144)=-3.84, p<.001$; Low slope $=-0.02, t(144)=-3.80, p<.001)$. In support of the buffering hypothesis, these results indicate that engaging in high levels of behavioral Muslim religious coping attenuates the negative effects of acculturative stress on life satisfaction.

Acculturative stress and Muslim religious coping as predictors of psychological symptoms. In line with the first set of analyses, demographic variables of age, generation status, education and English proficiency were entered as controls in the first step. At Step 2, acculturative stress significantly predicted 
Figure 1: The Interactive Effects of Acculturative Stress and Behavioral Muslim Religious Coping on Life Satisfaction

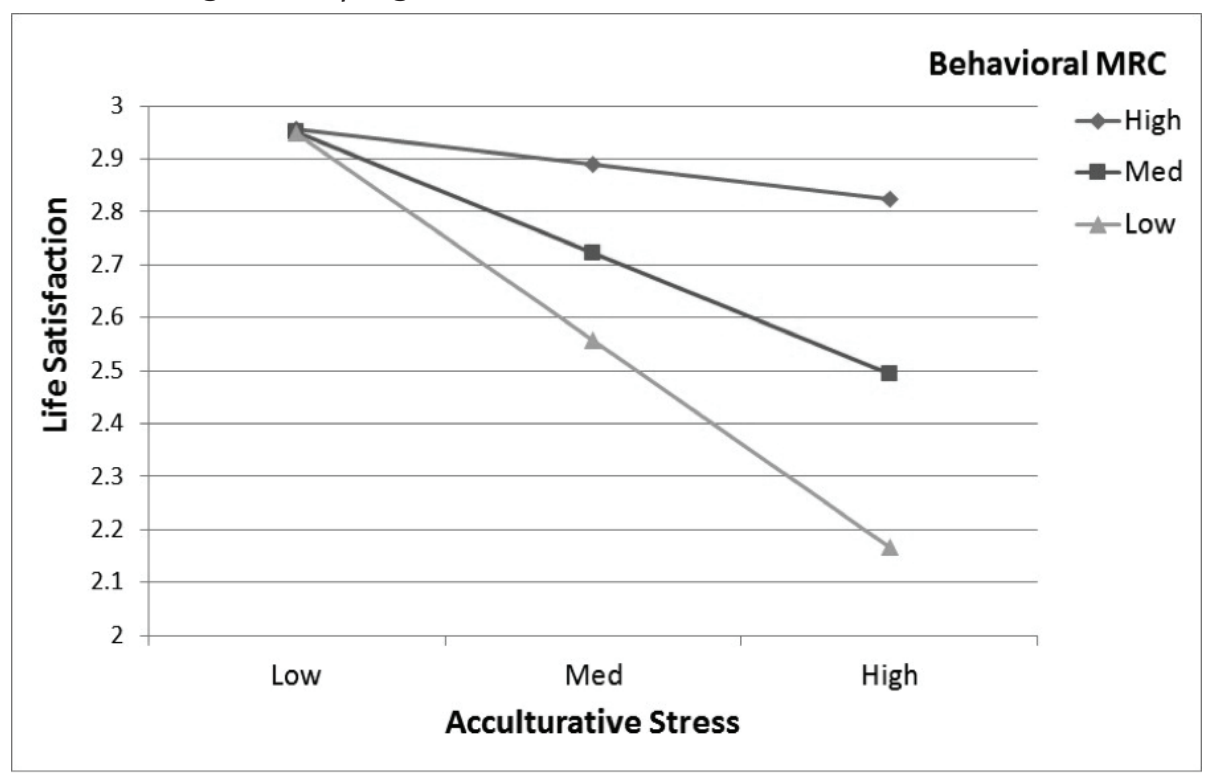

increased psychological symptoms $(\beta=0.37, t=-4.58, p<.001)$, accounting for $16.8 \%$ of the variance $\left(\Delta R^{2}=0.12, F(1,141)=21.00, p<.001\right)$. Consistent with our hypothesis, higher rates of acculturative stress predicted increased psychological symptoms of distress.

Cognitive, Behavioral and Social MRC were entered into separate regression analyses at Step 3; however, contrary to hypotheses, all failed to explain additional variance in psychological symptoms (Cognitive MRC $\beta=-0.05, t$ $=-0.62, p=.54$; Behavioral MRC $\beta=-0.05, t=-0.58, p=.56$; Social MRC $\beta$ $=-0.13, t=-1.60, p=.11)$. Furthermore, none of the interaction effects were significant on the final step (Cognitive MRC $\mathrm{x}$ acculturative stress $\beta=-0.11$, $t=0.26, p=.79$; Behavioral MRC $\mathrm{x}$ acculturative stress $\beta=-0.12, t=-0.34$, $p=.73$; Social MRC $\mathrm{x}$ acculturative stress $\beta=-0.42, t=-1.95, p=.05)$. These findings indicate that acculturative stress is a significant predictor of increased psychological symptoms, yet no dimension of Muslim Religious Coping exerts an independent influence on psychological symptoms, nor do they function as buffers.

\section{Discussion}

This study aimed to investigate the inter-relationships between acculturative stress, religious coping and subjective wellbeing among New Zealand Muslims. It was of interest in this study to determine whether religion acted as a coping 
resource among Muslims living as minorities in the West, who are experiencing unique acculturative stressors including religious discrimination and barriers to integration.

Hypotheses regarding the inter-relationships between acculturative stress, religious coping, and subjective wellbeing were partially supported. As predicted, acculturative stress predicted lower life satisfaction and greater psychological symptoms. Muslim Religious Coping independently predicted greater life satisfaction; however, it failed to produce a significant influence on psychological symptoms. Additionally, behavioral MRC emerged as a significant moderator of the link between acculturative stress and life satisfaction. Contrary to hypotheses, no dimension of Muslim religious coping moderated the relationship between acculturative stress and psychological symptoms.

The finding that acculturative stress directly predicts poorer life satisfaction and increased psychological symptoms of distress is consistent with previous research (Berry et al., 2006; Schmitt, Branscombe, Postmes, \& Garcia, 2014). These findings suggest that the acculturative experiences of Muslims in New Zealand mirror the patterns of other ethnic minorities around the world. While different communities may be experiencing group-specific stressors, the link between appraised distress and poor wellbeing remains robust among this population.

The finding that religious coping both independently enhances life satisfaction, as well as moderates the stress-wellbeing relationship, provides some support for both the main effect hypothesis and the buffering hypothesis described by Ensel and Lin (1991). Both cognitive and social Muslim religious coping independently predicted life satisfaction, regardless of stress. Ensel and Lin (1991) describe such psychosocial resources as distress-deterring, hypothesizing that their effectiveness lies in strengthening and reinforcing a person's base psychological state.

Cognitive religious coping may provide believers with a religious framework they can draw upon to apply sacred meaning to their lives, which is likely to provide an enhanced sense of coherence in times of blessing as well as times of distress (Aflakseir, 2012; Pargament, 1997). Belief systems may influence the way a specific life event is viewed and interpreted, the sense of control one feels over life events and the ability to persevere and achieve solutions (Park, Cohen, \& Herb, 1990).

The finding that social religious coping directly predicts life satisfaction is consistent with previous research, which has demonstrated public religious participation as a reliable predictor of wellbeing (Koenig \& Larson, 2001; Reyes-Ortiz et al., 2008). Social religious engagement may assist in cultivating a sense of religious identity or developing a shared sense of meaning and purpose. It may be that the presence of a community that bears a shared worldview 
is reinforcing for individuals experiencing a sense of alienation from the wider society. It may also be that instrumental support is offered from a religious congregation, through charity or counseling services (Ai, Huang, Bjorck, \& Appel, 2013; Stuart, 2012; Cohen \& Wills, 1985).

In support of the buffering hypothesis, it was found that behavioral MRC buffered the negative relationship between acculturative stress and life satisfaction. Thus, actively maintaining religious behaviors, despite potential barriers to religious maintenance, enhances life satisfaction. It may be that an increase in religious behaviors alleviates the dissonance experienced by those who are struggling to maintain their Islamic practices in a non-Muslim country (Yousaf \& Gobet, 2013). Additionally, while an increase in religious behaviors may predict increased discrimination frequency (Jasperse et al., 2012), the results here suggest that these behaviors also act as protective factors. These results are consistent with the findings of Jasperse et al. (2012) where Islamic practices protected against the detrimental effects of religious discrimination. This is also consistent with the Islamic concept of Taqwa (Divine protection and awareness of God), which is understood to be attained through the engagement of religious practices and may serve as spiritual protection in times of difficulty.

In contrast to the above findings, no dimension of Muslim religious coping emerged as predictive of psychological symptoms. This suggests that engaging in religious coping does not increase or alleviate symptoms of depression and anxiety. The reason behind this finding is unclear. Evidence from previous literature has demonstrated the independence of positive and negative outcomes, suggesting that subjective wellbeing is in fact a multi-dimensional construct (Diener, Suh, Lucas, \& Smith, 1999). A distinction can also be drawn between cognitive and affective measures of subjective wellbeing, with life satisfaction representing a cognitive component, and psychological symptoms capturing affective and physiological components of wellbeing (Diener, 2000). Religious coping may primarily influence cognitive wellbeing, in line with the Islamic principle of Qadr, or Divine Will. Muslims are encouraged to seek Ridaa (contentment) with their Qadr, and frequently use the phrase "Alhamdolillah (Praise be to God)" to capture this sense of contentment with their current circumstances (Abdel-Khalek, 2011). The findings in this study suggest that a turning towards religion may be effective by facilitating a process of deriving Ridaa among Muslims facing adversity.

The results suggest there is no guarantee that contentment at a cognitive level will result in an immediate alleviating of affective and physical symptoms of distress. Symptomatic measures are more sensitive to situational factors and tend to be short-term and subject to constant fluctuation, whereas a measure of satisfaction with life tends to remain fairly consistent over time (Diener, 2000). It may be that religious coping operates more as a resilience mechanism, by en- 
hancing more stable, positive measures of wellbeing and bolstering the psychological equilibrium of an individual. Although the short-term effects of stress are still apparent in anxiety and somatic symptoms, the use of religious coping appears to enhance an overall sense of satisfaction with one's life, thus potentially protecting against the long term effects of distress (Heisel \& Flett, 2004).

The field of positive psychology argues for a need to shift from a deficit model of health, where wellbeing is primarily determined by the absence of illness, to an additive model where wellness is the focus in its own right (Becker \& Rhynders, 2012). There is a growing recognition that simply working towards the alleviation of negative symptomatology does not achieve wellbeing and that individuals who rate themselves highly on measures of happiness and life satisfaction are not necessarily free from physical illness. Sniders (2006) outlines 11 positive traits and qualities identified by Positive Psychologists as integral in achieving enhanced subjective wellbeing. Of these qualities, many are embedded in the worldview and teachings of Islam, including hope, optimism, resilience, forgiveness, and gratitude. These traits are expected to contribute towards a more developed sense of coherence and personal meaning in life, two central aspects offered by religion (Aflakseir, 2012). The results here indicate that while Muslim religious coping may not be efficacious in reducing physical symptoms of distress in the short term, it may hold a pivotal role in the enhancement of quality of life.

\section{Strengths, Limitations and Future Directions}

The research addresses the important and timely issue of the role of religion in Muslims' experiences of acculturation and adaptation in Western societies. In doing so, the study synthesizes theory and research on acculturation and religion, advancing our understanding of coping with the challenges of intercultural contact. Just as importantly, the study has practical applications for the ways in which the reception of Muslim immigrants and their descendants in Western countries can foster their inclusion, subjective wellbeing and ultimately their capacity to make a valuable contribution to the wider society.

The study relied upon new instruments for the assessment of acculturative stress and religious coping. This is both a strength and a weakness. The strengths lie in the instruments' constructions, which address criticisms of the measurements of acculturative stress (Rudmin, 2009) and provide a more comprehensive and culturally appropriate assessment of religious coping for Muslims based on earlier work by Aflakseir and Coleman (2011) and Boudreaux et al. (1995). At the same time, future research further confirming the scales' reliability and validity would be beneficial. Additionally, while clear associations have been demonstrated among stress, coping and wellbeing, the limitations of 
a cross-sectional study apply here. Longitudinal data would be valuable in documenting the temporal pattern of these relationships throughout ongoing cultural transition and in response to local and global incidences of Islamophobia.

A further limitation is the nature of the sample, which self-reported a high degree of religiosity. This may account for the efficacious nature of religious coping found in this study (Krägeloh et al., 2012). Future research would need to explore a broader cross-section of the Muslim community in New Zealand, to determine the conditions under which religious coping is effective. Further, this study only examined two indicators of subjective wellbeing. Further research could look at other dimensions of wellbeing including positive affect and flourishing as well as objective measures, including health status. Finally, the research was conducted in a single country, New Zealand, which is known to be relatively accepting of cultural diversity. The extent to which Muslim religious coping functions as a resource in relatively intolerant environments remains to be examined.

\section{Concluding Comments: Implications and Applications}

In considering the findings that Muslim religious coping enhances positive wellbeing outcomes, mental health research has increasingly recognized religion and spirituality as important variables to consider in therapeutic practice (Pargament, 1997, 2011), with studies showing that many clients prefer to include their spiritual beliefs and resources in therapy (Tisdale, 2003). The movement towards 'spiritually-integrated therapy' advocates for a more holistic paradigm, acknowledging mind, body, and spirit as components of mental health. In particular, traditional cognitive therapy has been identified as a good fit for a diverse range of religious traditions and mental disorders (Azhar, Varma, \& Dharap, 1994; Hodge, 2006; McCullough, 1999).

In line with the broader literature, a review of the research on Muslim mental health has advocated for the importance of religiously integrated psychotherapy when working with Muslim clients (Abu Raiya \& Pargament, 2010; Hodge \& Nadir, 2008). Many minority groups access mental healthcare at disproportionately low rates, yet Muslims are recognized as under-represented even relative to other ethnic and religious minorities (Cinnirella \& Loewenthal, 1999; Kelly, Aridi, \& Bakhtiar, 1996). A key barrier identified for Muslims is a lack of perceived 'fit' between their needs and the current services offered by healthcare providers (Abu Raiya \& Pargament, 2010; Kelly et al., 1996). Nevertheless, a number of authors argue that Western-based cognitive therapy is in fact a good fit for traditional Islamic thought, drawing many parallels between Islamic teachings and core concepts of cognitive therapy (Azhar et al., 1994; Hodge \& Nadir, 2008). 
The current research supports the notion of an Islamically-based cognitive therapy as a valuable contribution to psychological practice. Previous attempts to develop Islamically-integrated interventions have focused primarily on cognitive restructuring techniques that incorporate a religious worldview (Hodge \& Nadir, 2008; Azhar et al., 1994). However, the present findings suggest that the strength of an Islamic model of therapy exists more broadly than within cognitive models alone, indicating the importance of the inward, outward, and collective aspects of the faith in coping with adversity. While cognitive religious coping techniques were indeed demonstrated as efficacious in enhancing wellbeing, similar effects were also apparent for the behavioral and social components of religious coping. Thus a Cognitive-Behavioral model that integrates the mind, body, and social environment of a client with their religious paradigm is likely to enhance effectiveness of treatment.

Further, the finding that religion is a valuable resource in the lives of Muslims is important not only at the individual level of psychosocial intervention, but also at a socio-political level. In the context of an Islamophobic climate, this research provides support for a growing voice arguing for the promotion of religious maintenance and freedom of practice for members of this faith group (e.g., Jasperse et al., 2012). The results provide further evidence to the ramifications of policy changes that restrict the rights of Muslims to practice their religion. Several European countries have established legislation to ban religious attire in public places, which has focused heavily on Islamic dress in its implementation. While most Western nations that emphasize integration and multiculturalism have not followed suit, the detrimental effects of Anti-Terror and surveillance laws on Muslim populations across the West are beginning to emerge. While this shift in policy purports the idea that Islam is a threat, our results suggest that the healthy practice of this religion is in fact associated with positive outcomes. This study points towards Islam as a source of benefit and positivity among its members, even where they live as minorities. This carries an important message towards individuals and policy makers alike- that there is still a place for the open practice of Islam in modern societies.

\section{References}

Abdel-Khalek, A. M. (2011). Subjective wellbeing and religiosity in Egyptian college students. Psychological Reports, 108(1), 54-58. https://doi.org/10.2466/07.17. PR0.108.1.54-58

Abu Raiya, H., \& Pargament, K. I. (2010). Religiously integrated psychotherapy with Muslim clients: From research to practice. Professional Psychology: Research and Practice, 41(2), 181-188. https://doi.org/10.1037/a0017988 
Abu Raiya, H., \& Pargament, K. I. (2011). Empirically based psychology of Islam: Summary and critique of the literature. Mental Health, Religion \& Culture, 14(2), 93115. https://doi.org/10.1080/13674670903426482

Abu Raiya, H., Pargament, K. I., \& Mahoney, A. (2011). Examining coping methods with stressful interpersonal events experienced by Muslims living in the United States following the 9/11 attacks. Psychology of Religion and Spirituality, 3(1), 1-14. https://doi.org/10.1037/a0020034

Abu Raiya, H., Pargament, K. I., Mahoney, A., \& Stein, C. (2008). A psychological measure of Islamic religiousness: Development and evidence for reliability and validity. The International Journal for the Psychology of Religion, 18(4), 291-315. https:// doi.org/10.1080/10508610802229270

Adam, Z. (2015). Acculturative stress, faith-based coping and wellbeing amongst New Zealand Muslims. Unpublished Master's thesis. Victoria University of Wellington, New Zealand.

Aflakseir, A. (2012). Religiosity, personal meaning, and psychological wellbeing: A study among Muslim students in England. Pakistan Journal of Social and Clinical Psychology, 9(2), 27-31.

Aflakseir, A., \& Coleman, P. G. (2009). The influence of religious coping on the mental health of disabled Iranian war veterans. Mental Health, Religion and Culture, 12(2), 175-190. https://doi.org/10.1080/13674670802428563

Aflakseir, A., \& Coleman, P. G. (2011). Initial development of the Iranian religious coping scale. Journal of Muslim Mental Health, 6(1), 44-61. https://doi.org/10.3998/ jmmh.10381607.0006.104

Ahmed, S. R., Kia-Keating, M., \& Tsai, K. H. (2011). A structural model of racial discrimination, acculturative stress, and cultural resources among Arab American adolescents. American Journal of Community Psychology, 48(3-4), 181-192. https:// doi.org/10.1007/s10464-011-9424-3

Ai, A. L., Huang, B., Bjorck, J., \& Appel, H. B. (2013). Religious attendance and major depression among Asian Americans from a national database: The mediation of social support. Psychology of Religion and Spirituality, 5(2), 78-89. https://doi. org/10.1037/a0030625

Aroian, K. J., Hough, E. S., Templin, T. N., Kulwicki, A., Ramaswamy, V., \& Katz, A. (2009). Model of mother-child adjustment in Arab Muslim immigrants to the U.S. Social Science and Medicine, 69, 1377-1386. https://doi.org/10.1016/j.socscimed.2009.08.027

Ano, G. G., \& Vasconcelles, E. B. (2005). Religious coping and psychological adjustment to stress: A meta-analysis. Journal of Clinical Psychology, 61(4), 461-480. https://doi.org/10.1002/jclp.20049

Aydin, N., Fischer, P., \& Frey, D. (2010). Turning to God in the face of ostracism: Effects of social exclusion on religiousness. Personality and Social Psychology Bulletin, 36(6), 742-753. https://doi.org/10.1177/0146167210367491

Azhar, M. Z., Varma, S. L., \& Dharap, A. S. (1994). Religious psychotherapy in anxiety disorder patients. Acta Psychiatrica Scandinavica, 90(1), 1-3. https://doi. org/10.1111/j.1600-0447.1994.tb01545.x

Becker, C. M., \& Rhynders, P. (2012). It's time to make the profession of health about health. Scandinavian Journal of Public Health, 41, 1-3. https://doi. org/10.1177/1403494812467506 
Berry, J. W. (1997). Immigration, acculturation, and adaptation. Applied psychology, 46(1), 5-34. https://doi.org/10.1111/j.1464-0597.1997.tb01087.x

Berry, J. W. (2006). Acculturative stress. In P. T. P. Wong \& L. C. J. Wong (Eds.), Handbook of multicultural perspectives on stress and coping (pp. 287-298). Dallas: Spring Publications. https://doi.org/10.1007/0-387-26238-5_12

Berry, J. W., Phinney, J. S., Sam, D. L., \& Vedder, P. (Eds.) (2006). Immigrant youth in cultural transition: Acculturation, identity and adaptation across national contexts. Mahwah, NJ: Lawrence Erlbaum Associates, Inc.

Berry, J. W., \& Sam, D. L. (2016). Acculturation: Conceptual background and theoretical perspectives. In D. L. Sam \& J. W. Berry (Eds.), Cambridge handbook of acculturation psychology (2 ${ }^{\text {nd }}$ ed., pp. 11-29). Cambridge, UK: Cambridge University Press. https://doi.org/10.1017/CBO9781316219218.003

Bhui, K., King, M., Dein, S., \& O'Connor, W. (2008). Ethnicity and religious coping with mental distress. Journal of Mental Health, 17(2), 141-151. https://doi. org/10.1080/09638230701498408

Boudreaux, E., Catz, S., Ryan, L., Amaral-Melendez, M., \& Brantley, P. J. (1995). The ways of religious coping scale: Reliability, validity, and scale development. Assessment, 2(3), 233-244. https://doi.org/10.1177/1073191195002003004

Carpenter, T. P., Laney, T., \& Mezulis, A. (2012). Religious coping, stress, and depressive symptoms among adolescents: A prospective study. Psychology of Religion and Spirituality, 4(1), 19-30. https://doi.org/10.1037/a0023155

Carver, C. S., Scheier, M. F., \& Weintraub, J. K. (1989). Assessing coping strategies: A theoretically based approach. Journal of Personality and Social Psychology, 56(2), 267-283. https://doi.org/10.1037/0022-3514.56.2.267

Cinnirella, M., \& Loewenthal, K. M. (1999). Religious and ethnic group influences on beliefs about mental illness: A qualitative interview study. British Journal of Medical Psychology, 72(4), 505-524. https://doi.org/10.1348/000711299160202

Cohen, S., \& Wills, T. A. (1985). Stress, social support, and the buffering hypothesis. Psychological Bulletin, 98(2), 310-357. https://doi.org/10.1037/0033-2909.98.2.310

Crockett, L. J., Iturbide, M. I., Torres Stone, R. A., McGinley, M., Raffaelli, M., \& Carlo, G. (2007). Acculturative stress, social support, and coping: Relations to psychological adjustment among Mexican American college students. Cultural Diversity and Ethnic Minority Psychology, 13(4), 347-355. https://doi.org/10.1037/10999809.13.4.347

Diener, E. (1994). Assessing subjective wellbeing: Progress and opportunities. Social Indicators Research, 31, 103-157. https://doi.org/10.1007/BF01207052

Diener, E. (2000). Subjective wellbeing: The science of happiness and a proposal for a national index. American Psychologist, 55(1), 34-43. https://doi.org/10.1037/0003066X.55.1.34

Diener, E. (2006). Guidelines for national indicators of subjective wellbeing and illbeing. Journal of Happiness Studies, 7, 397-404. https://doi.org/10.1007/s10902006-9000-y

Diener, E., Emmons, R. A., Larsen, R. J., \& Griffin, S. (1985). The Satisfaction with Life Scale. Journal of Personality Assessment, 49, 71-75. https://doi.org/10.1207/ s15327752jpa4901_13

Diener, E., Suh, E. M., Lucas, R. E., \& Smith, H. L. (1999). Subjective wellbeing: Three decades of progress. Psychological Bulletin, 125(2), 276-302. https://doi. org/10.1037/0033-2909.125.2.276 
Ensel, W. M., \& Lin, N. (1991). The life stress paradigm and psychological distress. Journal of Health and Social Behavior, 321-341. https://doi.org/10.2307/2137101

Fernandez, A., \& Loukas, A. (2014). Acculturation and religious coping as moderators of the association between discrimination and depressive symptoms among Mexican-American vocational students. Journal of Immigrant and Minority Health, 16(6), 1290-1293. https://doi.org/10.1007/s10903-013-9952-z

Gardner, T. M., Krägeloh, C. U., \& Henning, M. A. (2014). Religious coping, stress, and quality of life of Muslim university students in New Zealand. Mental Health, Religion \& Culture, 17(4), 327-338. https://doi.org/10.1080/13674676.2013.804044

Hackney, C. H., \& Sanders, G. S. (2003). Religiosity and mental health: A meta-analysis of recent studies. Journal for the scientific study of religion, 42(1), 43-55. https://doi. org/10.1111/1468-5906.t01-1-00160

Harrison, M. O., Koenig, H. G., Hays, J. C., Eme-Akwari, A. G., \& Pargament, K. I. (2001). The epidemiology of religious coping: A review of recent literature. International Review of Psychiatry, 13(2), 86-93. https://doi. org/10.1080/09540260124356

Hassouneh-Phillips, D. (2003). Strength and vulnerability: Spirituality in abused American Muslim women's lives. Issues in Mental Health Nursing, 24, 681-694. https://doi.org/10.1080/01612840305324

Heisel, M. J., \& Flett, G. L. (2004). Purpose in life, satisfaction with life, and suicide ideation in a clinical sample. Journal of Psychopathology and Behavioral Assessment, 26(2), 127-135. https://doi.org/10.1023/B:JOBA.0000013660.22413.e0

Hodge, D. R. (2006). Spiritually modified cognitive therapy: A review of the literature. Social Work, 51(2), 157-166. https://doi.org/10.1093/sw/51.2.157

Hodge, D.R., \& Nadir, A. (2008). Moving toward culturally competent practice with Muslims: Modifying cognitive therapy with Islamic tenets. Social Work, 53(1), 3141. https://doi.org/10.1093/sw/53.1.31

Jasperse, M., Ward, C., \& Jose, P. E. (2012). Identity, perceived religious discrimination, and Psychological well-being in Muslim immigrant women. Applied Psychology: An International Review, 61(2), 250-271. https://doi.org/10.1111/j.14640597.2011.00467.x

Jibeen, T., \& Khalid, R. (2010). Predictors of psychological wellbeing of Pakistani immigrants in Toronto Canada. International Journal of Intercultural Relations, 34, 452-464. https://doi.org/10.1016/j.ijintrel.2010.04.010

Joiner Jr, T. E., \& Walker, R. L. (2002). Construct validity of a measure of acculturative stress in African Americans. Psychological assessment, 14(4), 462-466. https://doi. org/10.1037/1040-3590.14.4.462

Jose, P.E. (2013). ModGraph-I: A programme to compute cell means for the graphical display of moderational analyses: The internet version, Version 3.0. Victoria University of Wellington, Wellington, New Zealand. Retrieved 28 August 2014 from http:// pavlov.psyc.vuw.ac.nz/paul-jose/modgraph/

Jose, P. E., Ward, C., \& Liu, J. (2007). Cross-cultural adaptation of Asian and Western international students in New Zealand. In J. H. Liu, C. Ward, A. Bernardo, M. Karasawa \& R. Fischer (Eds.) Casting the individual in societal and cultural contexts: Social and societal psychology for Asia and the Pacific (pp. 205-224). Seoul: Kyoyook-Kwahak-Sa Publishing Company.

Kelly, E. W., Aridi, A., \& Bakhtiar, L. (1996). Muslims in the United States: An exploratory study of universal and mental health values. Counseling and Values, 40(3), 206-218. https://doi.org/10.1002/j.2161-007X.1996.tb00853.x 
Khan, Z. H., \& Watson, P. J. (2006). Construction of the Pakistani Religious Coping Practices Scale: Correlations with religious coping, religious orientation, and reactions to stress among Muslim university students. The International Journal for the Psychology of Religion, 16(2), 101-112. https://doi.org/10.1207/s15327582ijpr1602_2

Kloek, M. E., Peters, K., \& Sijtsma, M. (2013). How Muslim women in the Netherlands negotiate discrimination during leisure activities. Leisure Sciences, 35(5), 405-421. https://doi.org/10.1080/01490400.2013.831285

Koenig, G., \& Larson, D. (2001). Religion and mental health: Evidence for an association. International Review of Psychiatry, 13(2), 67-78. https://doi. org/10.1080/09540260124661

Krägeloh, C. U., Chai, P. P. M., Shepherd, D., \& Billington, R. (2012). How religious coping is used relative to other coping strategies depends on the individual's level of religiosity and spirituality. Journal of religion and health, 51(4), 1137-1151. https://doi.org/10.1007/s10943-010-9416-x

Kuppens, P., Realo, A., \& Diener, E. (2008). The role of positive and negative emotions in life satisfaction judgment across nations. Journal of Personality and Social Psychology, 95, 66-75. https://doi.org/10.1037/0022-3514.95.1.66

Lazarus, R. S., \& Folkman, S. (1984). Stress, appraisal and coping. New York: Springer.

Liu, J. H., Wilson, M. S., McClure, J., \& Higgins, T. R. (1999). Social identity and the perception of history: Cultural representations of Aotearoa/New Zealand. European Journal of Social Psychology, 29, 1021-1047. https://doi.org/10.1002/(SICI)10990992(199912)29:8<1021::AID-EJSP975>3.0.CO;2-4

McCullough, M. E. (1999). Research on religion-accommodative counseling: Review and meta-analysis. Journal of Counseling Psychology, 46(1), 92-98. https://doi. org/10.1037/0022-0167.46.1.92

Pargament, K. I. (1997). The psychology of religion and coping: Theory, research, practice. New York: Guilford Press.

Pargament, K. I. (2011). Spiritually integrated psychotherapy: Understanding and addressing the sacred. New York: Guilford Press.

Pargament, K. I., Smith, B. W., Koenig, H. G., \& Perez, L. (1998). Patterns of positive and negative religious coping with major life stressors. Journal for the Scientific Study of Religion, 37(4), 710-724. https://doi.org/10.2307/1388152

Park, C., Cohen, L. H., \& Herb, L. (1990). Intrinsic religiousness and religious coping as life stress moderators for Catholics versus Protestants. Journal of Personality and Social Psychology, 59(3), 562-574. https://doi.org/10.1037/0022-3514.59.3.562

Pavot, W., \& Diener, E. (1993). Review of the Satisfaction with Life Scale. Psychological Assessment, 5, 164-172. https://doi.org/10.1037/1040-3590.5.2.164

Pedersen, A., Dunn, K., Forrest, J., \& McGarty, C. (2012). Prejudice and discrimination from two sides: How do Middle-Eastern Australians experience it and how do other Australians explain it? Journal of Pacific Rim Psychology, 6(1), 18-26. https:// doi.org/10.1017/prp.2012.3

Reyes-Ortiz, C. A., Berges, I. M., Raji, M. A., Koenig, H. G., Kuo, Y. F., \& Markides, K. S. (2008). Church attendance mediates the association between depressive symptoms and cognitive functioning among older Mexican Americans. The Journals of Gerontology Series A: Biological Sciences and Medical Sciences, 63(5), 480-486. https://doi.org/10.1093/gerona/63.5.480

Ritsner, M., Modai, H., \& Ponizovsky, A. (2000). The stress-support patterns and psychological distress of immigrants. Stress Medicine, 16, 139-147. https://doi. org/10.1002/(SICI)1099-1700(200004)16:3<139::AID-SMI840>3.0.CO;2-C 
Rudmin, F. (2009). Constructs, measurements and models of acculturation and acculturative stress. International Journal of Intercultural Relations, 33, 106-123. https:// doi.org/10.1016/j.ijintrel.2008.12.001

Sawatzky, R., Ratner, P. A., \& Chiu, L. (2005). A meta-analysis of the relationship between spirituality and quality of life. Social indicators research, 72(2), 153-188. https://doi.org/10.1007/s11205-004-5577-x

Schmitt, M. T., Branscombe, N. R., Postmes, T., \& Garcia, A. (2014). The consequences of perceived discrimination for psychological wellbeing: A meta-analytic review. Psychological Bulletin, 140(4), 921-948. https://doi.org/10.1037/a0035754

Sheridan, L. P. (2006). Islamophobia pre-and post-September 11th, 2001. Journal of Interpersonal Violence, 21(3), 317-336. https://doi.org/10.1177/0886260505282885

Sirin, S. R., \& Fine, M. (2007). Hyphenated selves: Muslim American youth negotiating identities on the fault lines of global conflict. Applied Development Science, 11(3), 151-163. https://doi.org/10.1080/10888690701454658

Sniders, K. (2006). Positive psychology: Let's get happy. Annals of the American Psychotherapy Association, 9, 34-35.

Statistics New Zealand (2013). 2013 Census Data. Retrieved 7 November 2014 from http://www.stats.govt.nz/Census/2013-census/

Stuart, J. (2012). Pathways to positive development for Muslim immigrant youth in Western contexts. (Unpublished doctoral dissertation). Victoria University of Wellington, New Zealand.

Stuart, J., \& Ward, C. (2011). A question of balance: Exploring the acculturation, integration and adaptation of Muslim immigrant youth. Journal of Psychosocial Intervention, 20, 255-267. https://doi.org/10.5093/in2011v20n3a3

Stuart, J., Ward, C. \& Adam, Z. (2010). Current issues in the development and acculturation of Muslim youth. Bulletin of the International Society for the Study of Behavioral Development, 2, 9-13.

Stuart, J., Ward, C., \& Robinson, L. (2016). The influence of family climate on stress and adaptation of Muslim immigrant young adults in two Western countries. International Perspectives in Psychology: Research, Practice, Consultation, 5, 1-17. https:// doi.org/10.1037/ipp0000043

Szabo, A., Ward, C., \& Jose, P. (2016). Uprooting stress, coping and anxiety: A longitudinal study of international students. International Journal of Stress Management, 23, 190-208. https://doi.org/10.1037/a0039771

Tisdale, T. C. (2003). Listening and responding to spiritual issues in psychotherapy: An interdisciplinary perspective. Journal of Psychology and Christianity, 22(3), 262-272.

Tix, A. P., \& Frazier, P. A. (1998). The use of religious coping during stressful life events: Main effects, moderation, and mediation. Journal of Consulting and Clinical Psychology, 66(2), 411-422. https://doi.org/10.1037/0022-006X.66.2.411

Torres, L., \& Rollock, D. (2004). Acculturative distress among Hispanics: The role of acculturation, coping, and intercultural competence. Journal of Multicultural Counseling and Development, 32(3), 155-167. https://doi.org/10.1002/j.2161-1912.2004. tb00368.x

Ward, C. (2011). The ABCs of acculturation. In D. Matsumoto (ed.), Handbook of culture and psychology (pp. 411-446). New York: Oxford University Press.

Ward, C., Bochner, S., \& Furnham, A. (2001). The psychology of culture shock. London: Routledge.

Ward, C., \& Liu, J. (2012). Ethno-cultural conflict in Aotearoa/New Zealand. In D. Lan- 
dis \& R. Albert (Eds.), Handbook of ethnic conflict: International perspectives (pp. 45-69). New York: Springer. https://doi.org/10.1007/978-1-4614-0448-4_3

Ward, C., \& Masgoret, A. M. (2008). Attitudes toward Immigrants, immigration, and multiculturalism in New Zealand: A social psychological analysis. International Migration Review, 42(1), 227-248. https://doi.org/10.1111/j.1747-7379.2007.00119.x

Yousaf, O., \& Gobet, F. (2013). The emotional and attitudinal consequences of religious hypocrisy: Experimental evidence using a cognitive dissonance paradigm. The Journal of Social Psychology, 153(6), 667-686. https://doi.org/10.1080/00224545. 2013.814620 